\title{
Sala virtual de apoio pedagógico: uma experiência durante as atividades de ensino remoto emergenciais
}

\author{
Ana Cristina do Amaral Lovato ${ }^{1}$ \\ Patrícia Forgiarini Firpo ${ }^{2}$
}

\section{RESUMO}

Apresenta-se, neste texto, as experiências pedagógicas virtuais realizadas para manter a oferta do apoio pedagógico a estudantes de graduação durante as Atividades de Ensino Remoto Emergenciais (AEREs), que ocorreram no período de isolamento social imposto pelo contexto pandêmico. A metodologia utilizada é o relato de experiência. Os resultados apontam que práticas virtuais de apoio têm impactos positivos quando os recursos usados atendem às necessidades dos estudantes e são coerentes com a nova realidade. Dessa forma, refletiu-se e fomentou-se discussões sobre o uso das tecnologias digitais e ambientes virtuais de interação na ampliação e consolidação do apoio pedagógico no Ensino Superior.

Palavras-chave: Interação. Ensino Remoto. Apoio pedagógico. Ambientes virtuais.

\footnotetext{
${ }^{1}$ analovato@unipampa.edu.br - Universidade Federal do Pampa

2 patriciafirpo@unipampa.edu.br - Universidade Federal do Pampa
} 


\section{Virtual pedagogical support room: an experience during emergential remote teaching activities}

\section{ABSTRACT}

We present in this text the virtual pedagogical experiences carried out to maintain the pedagogical support to undergraduate students during emergency remote teaching activities, which occurred during the period of social isolation imposed by the pandemic context. The methodology used is the experience report. The results show that virtual support practices have positive impacts when the resources used meet the needs of students and are consistent with the new reality. In this way, we reflect and encourage discussions about the use of digital technologies and virtual environments for interaction in the expansion and consolidation of pedagogical support in higher education.

Keywords: Interaction. Remote teaching. Pedagogical support. Virtual environments. 
Em fevereiro de 2020, foi declarada emergência em saúde pública no Brasil, devido à pandemia causada pela COVID-19, e publicada a Lei $n^{\circ} 13.979$, que dispõe sobre as medidas de enfrentamento da emergência, que preveem, dentre outras recomendações, o afastamento social, o que acarretou na suspensão das aulas presenciais. Tais acontecimentos provocaram muitos desafios à educação, pois impuseram novas práticas educativas de forma rápida e emergencial, na tentativa de minimizar prejuízos na aprendizagem dos estudantes, além de outras consequências, como o aumento do índice de evasão (BRASIL, 2020).

Desse modo, visando a conter o contágio entre as pessoas e a disseminação da doença causada pelo novo coronavírus, foi adotado o Ensino Remoto Emergencial (ERE), que consiste em uma modalidade de ensino em que há o distanciamento geográfico de professores e estudantes. Nessa configuração do ensino, há uma transposição de metodologias e práticas da sala de aula presencial física para os meios on-line, sendo este um modelo temporário (MOREIRA; SCHLEMMER, 2020).

As instituições de ensino se reinventaram, conectando-se, ainda mais, por meio de diferentes ferramentas digitais, adotando principalmente plataformas digitais de aprendizagem ou ambientes virtuais de aprendizagem, que ganharam força e estão mais presentes nos processos de ensino do que nunca. Na Educação Superior não foi diferente: com as restrições impostas pela pandemia e as medidas de isolamento social, além das atividades acadêmicas, as atividades técnicas e administrativas também sofreram modificações e adequações ao novo contexto.

A tecnologia foi fundamental para a continuidade dessas atividades, porém, mesmo que muitas pessoas já utilizassem diferentes tecnologias digitais no dia a dia, é preciso que se leve em consideração que vários estudantes do Ensino Superior não possuíam acesso efetivo e de qualidade aos bens da cibercultura, tornando ainda maior o desafio de manter a continuidade dos serviços oferecidos pela universidade, dentre eles o apoio pedagógico ao estudante, foco do presente relato.

Considera-se que a distância física foi um dos maiores desafios ao acompanhamento pedagógico dos estudantes durante o processo de aprendizagem remota emergencial. Esse cenário motivou o planejamento e elaboração de estratégias pedagógicas a fim de manter a proximidade com a comunidade acadêmica.

O objetivo deste texto é apresentar as experiências vividas por meio de práticas pedagógicas virtuais desenvolvidas pela equipe de apoio pedagógico do Núcleo de Desenvolvimento Educacional (NuDE) da Universidade Federal do Pampa (UNIPAMPA), para manter a oferta da assistência acadêmica aos estudantes dos cursos de graduação da instituição durante as Atividades de Ensino Remoto Emergenciais (AEREs). $O$ objeto de estudo foram as práticas pedagógicas realizadas no Ambiente Virtual de Aprendizagem (AVA), as quais poderão desencadear potenciais contribuições para o desenvolvimento acadêmico.

Com o intuito de que este trabalho traga colaborações no âmbito educacional, por meio do incentivo ao uso de novos métodos de apoio pedagógico em instituições de Ensino Superior, 
analisou-se as metodologias utilizadas durante as atividades na sala virtual, refletindo-se sobre o uso das tecnologias digitais para ampliação e consolidação do apoio pedagógico. Dessa forma, deu-se destaque à implementação, apresentação e configuração de um ambiente virtual que possibilitasse as estratégias de personalização, interação e colaboração no processo de aprendizagem a partir da flexibilização de espaços e tempos para atender as necessidades dos estudantes.

Assim sendo, este trabalho configura uma pesquisa de enfoque qualitativo, do tipo relato de experiência, pois busca, por meio da socialização das práticas utilizadas, colaborar para o desenvolvimento, qualificação e fortalecimento das atividades pedagógicas na área da educação. Para tanto, tem-se como dados de investigação os registros, observações e interações estabelecidas a partir da implementação da Sala Virtual de Apoio Pedagógico e o acompanhamento das atividades propostas no AVA.

Parte-se do entendimento que aprender envolve interação entre aqueles que participam do processo e compreende-se que o apoio pedagógico ao estudante, durante a sua trajetória no Ensino Superior, tem potencializado o engajamento discente no seu próprio processo de aprender, conectando-o ao contexto universitário, favorecendo um maior desempenho acadêmico e o sentimento de pertencimento à instituição. Desse modo, considera-se que essa conexão é essencial, principalmente por se conhecer os desafios postos pelas grandes transformações que têm ocorrido no âmbito acadêmico; em especial, no que se refere às práticas sociais efetivadas por e com grupos sociais tão diversos que hoje fazem parte das universidades graças às políticas de expansão, interiorização e democratização do Ensino Superior.

Neste texto, apresenta-se inicialmente um breve histórico da implementação e desenvolvimento do apoio pedagógico na Unipampa, a fim de situar o leitor à especificidade do contexto profissional. A partir de então, descreve-se as atividades realizadas com o objetivo de efetivar o apoio pedagógico no campus da instituição e, na sequência, analisa-se e reflete-se sobre as alternativas utilizadas para manter esse suporte aos estudantes, mesmo com as limitações impostas pelo contexto pandêmico. Por fim, faz-se considerações a respeito dos impactos da experiência na prática profissional e as possibilidades de ações futuras idealizadas após a análise dos resultados do trabalho desenvolvido.

\section{APOIO PEDAGÓGICO NA UNIPAMPA: IMPLEMENTAÇÃO E DESENVOLVIMENTO}

Nas últimas duas décadas, vivenciamos o processo de expansão do Ensino Superior, fomentado principalmente pelas políticas governamentais para democratizá-lo, com destaque para o Reuni - Decreto $n^{0}$ 6.096, de 24 de abril de 2007 -, que dentre outros objetivos voltados para o acesso e permanência de estudantes visava, em um período de dez anos, dobrar o número de estudantes nos cursos de graduação. Somando-se a isso, também destacamos como políticas que contribuíram para ampliar o acesso às universidades federais o Sistema de Seleção Unificada (Sisu) e a Lei das Cotas - Lei 12.711/2012 de 29 de agosto de 2012 (DIAS; SAMPAIO, 2020).

No âmbito das ações da política de expansão e renovação das Instituições Federais de Ensino Superior (IFES) que a Unipampa, nosso contexto profissional, foi implementada. A Universidade Federal do Pampa (UNIPAMPA) fez parte do programa de expansão das 
universidades federais no Brasil. Um acordo de cooperação técnica firmado entre o Ministério da Educação (MEC), a Universidade Federal de Santa Maria (UFSM) e a Universidade Federal de Pelotas (UFPel) previu a ampliação do Ensino Superior na metade sul do estado do Rio Grande do Sul. Visando, assim, promover desenvolvimento regional de "um extenso território, com problemas no processo de desenvolvimento, inclusive de acesso à Educação Básica e à Educação Superior - a 'Metade Sul' do Rio Grande do Sul” (UNIPAMPA, 2013, p. 13).

Sabemos que, com a democratização do Ensino Superior, passam a fazer parte do contexto universitário grupos de pessoas que historicamente estiveram à margem da universidade, modificando sobremaneira o perfil dos alunos das instituições de Ensino Superior, que outrora era constituído majoritariamente pela elite dominante. Conforme Dias e Sampaio (2020):

Assim, além da ampliação no número de alunos, houve uma mudança no perfil
do corpo discente. Essas mudanças vieram acompanhadas de novas políticas
de permanência e assistência estudantil, que têm como marco a publicação da
Portaria Normativa $39 / 2007$, que criou o Programa Nacional de Assistência
Estudantil (PNAES), fortalecido pelo Decreto $7234 / 2010$. Nesses instrumentos
legais o apoio pedagógico passou a ser visto como área de atuação para as
políticas institucionais de permanência, criando as condições para que as
instituições fortalecessem seus serviços e, para muitas, a demanda de ações
para atender a essa área (DIAS; SAMPAIO, 2020, p. 5).

Ainda que as políticas públicas tenham se tornado cada vez mais sensíveis para a garantia de acesso, assegurando igualdade de condições a grupos sociais cada vez mais diversos, há carência de maior planejamento e de projetos institucionais que visem à permanência desses alunos na universidade.

Segundo Dias e Sampaio (2020), esse cenário impulsionou a contratação de profissionais que atendessem as demandas de apoio pedagógico e assistência estudantil nas universidades federais. Profissionais estes que, a princípio, não possuíam experiências anteriores no Ensino Superior ou formação inicial que preparasse para a nova realidade, além de não haver estudos e materiais suficientes que pudessem guiar o trabalho. Sendo assim, tornou-se uma prática profissional desafiadora.

A implementação e estruturação do apoio pedagógico na Unipampa teve início no ano de 2010. Nesse ano, a universidade, que estava em pleno processo de expansão, ampliou o quadro de servidores técnicos administrativos, dentre eles os técnicos em assuntos educacionais e assistentes sociais. Com a chegada desses profissionais, constituiu-se um núcleo denominado Núcleo de Desenvolvimento Educacional (NuDE), com o objetivo de apoiar diferentes atividades pedagógicas e de assistência estudantil em cada unidade acadêmica, visto que a instituição é composta de dez campi.

Entre 2011 e 2013, com a ampliação do número de cursos de graduação e atuação mais significativa da universidade em atividades de extensão e pesquisa, as demandas referentes ao apoio pedagógico e assistência estudantil aumentaram. Os atendimentos ao público discente tomaram uma proporção bastante significativa e complexa. Foi necessário, então, ampliar o quadro de profissionais especializados. Em 2014, pedagogos passaram a integrar os núcleos. A 
partir desse ano, começou o processo de estabelecimento de uma política de apoio pedagógico na instituição.

Atualmente, os núcleos são constituídos por uma equipe multiprofissional que conta com assistentes sociais, pedagogos e técnicos em assuntos educacionais em sua estrutura básica, podendo, ainda, incluir outros profissionais, de acordo com a necessidade de cada unidade. São duas frentes de trabalho, que muitas vezes atuam de maneira independente, mas que se complementam para chegar ao objetivo de promover o desenvolvimento acadêmico. Por um lado, estamos diretamente ligados à Pró-reitoria de Assuntos Estudantis e Comunitários (PRAEC), cujas ações são mais voltadas para a assistência estudantil e, por outro lado, desenvolvemos atividades orientadas pela Pró-Reitoria de Graduação (PROGRAD), voltadas para o apoio pedagógico.

As ações de apoio pedagógico, de maneira geral, visam a proporcionar ao estudante orientação e acompanhamento na sua trajetória acadêmica, além de promover atendimento individual e coletivo, a fim de sanar as dificuldades de aprendizagem que possam interferir no processo educativo, contribuindo, assim, para o desenvolvimento e sucesso acadêmico.

Nesse contexto, cientes dos desafios profissionais que nos são demandados diariamente, fomentamos, no âmbito do NuDE desde a sua implantação, diversas ações voltadas ao apoio pedagógico como forma de acolher e auxiliar na trajetória acadêmica e formativa dos estudantes de graduação vindos de realidades socioculturais tão diversas. E durante esse período especial de Ensino Remoto Emergencial não foi diferente. Impulsionadas pelas novas relações impostas pela necessidade de afastamento social, as quais são possíveis por meio das tecnologias, reelaboramos nossos planejamentos e transformamos nossas práticas profissionais, que, hoje em dia, são possíveis graças ao potencial de interação e conectividade dos ambientes virtuais.

\subsection{O Apoio Pedagógico ao Estudante no Campus Dom Pedrito}

No Campus Dom Pedrito, integram o Núcleo de Desenvolvimento Educacional, no ano de 2020, quatro técnicos administrativos em educação: uma assistente social, uma pedagoga, uma técnica em assuntos educacionais e um assistente em administração. A equipe atua no planejamento e execução de atividades de apoio pedagógico e assistência estudantil no âmbito local, estando diretamente ligada à coordenação acadêmica.

Os profissionais do NUDE colaboram em ações de acolhida e acompanhamento dos estudantes, participam de comissões locais e institucionais, realizam estudos e colaboram em projetos e grupos de pesquisa e extensão. Apesar disso, as atividades de apoio pedagógico são fomentadas e desenvolvidas principalmente no âmbito de nossas funções - pedagoga e técnica em assuntos educacionais -, em que desenvolvemos orientação pedagógica e acadêmica por meio de oficinas, cursos, palestras e rodas de conversa; acompanhamos programas institucionais de apoio à aprendizagem ofertados pela PROGRAD e PRAEC; além de coordenarmos projetos de ensino que visam a auxiliar o estudante no seu percurso de aprendizagem, desde o ingresso na universidade até a conclusão.

Para atender a essas demandas, sem contar as atividades de apoio presenciais, atividades técnicas e administrativas demandadas pela instituição de maneira geral, elaboramos, 
desenvolvemos e coordenamos projetos de ensino que possuem como foco o suporte aos universitários por meio da interação em ambientes virtuais de aprendizagem. Assim, dentre as ações de apoio pedagógico, o NuDE do Campus Dom Pedrito tem ofertado aos estudantes universitários, desde o ano de 2017, cursos on-line de curta duração, realizados no AVA Moodle institucional, tendo como objetivo, para além da construção de conhecimentos baseados nos conteúdos temáticos específicos de cada curso, fomentar a interação entre os participantes, facilitando a construção de redes de apoio na forma de comunidades colaborativas de aprendizagem on-line. Tais experiências anteriores foram fundamentais para que pudéssemos implementar a Sala Virtual de Apoio Pedagógico ao estudante no ano de 2020 e manter os serviços oferecidos aos alunos, mesmo com todos os desafios impostos pelo contexto pandêmico.

A motivação que tem nos levado a desenvolver práticas pedagógicas em contextos virtuais e interativos, dá-se em especial por acreditarmos que também no Ensino Superior presencial as tecnologias digitais virtuais podem - e devem - ser inseridas nos processos de ensino e de aprendizagem, uma vez que estão incorporadas naturalmente na vida da maioria das pessoas. Nesse sentido, Pinheiro (2009, p. 205) contribui com nossas reflexões ao abordar a temática dos gêneros no mundo digital, defendendo a inserção das tecnologias da informação e comunicação no âmbito educacional, visto que têm a potencialidade de "reordenar o próprio modo como o ser humano interage e se integra socialmente".

Para Soares (2002, p. 14), com a chegada da internet e das tecnologias da informação e comunicação, surgem "práticas de leitura e escritas digitais", caracterizadas como "letramento na cibercultura". Os estudos dessa autora oferecem aporte teórico para planejar nossas atividades, tendo como base a necessidade de fomentar práticas de letramentos acadêmicos, inclusive nos contextos virtuais, legitimados como novos ambientes sociais, em que as relações entre as pessoas se efetivam. A autora afirma que esses novos espaços trazem "significativas mudanças nas formas de interação entre escritor e leitor, entre escritor e texto, entre leitor e texto e até mesmo, mais amplamente, entre o ser humano e o conhecimento" (SOARES, 2002, p. 151).

Dentre as transformações sociais ocorridas com a popularização da internet está a possibilidade de aproximação de pessoas, independente da localização geográfica, criando situações dinâmicas em que tempos e espaços são ampliados e ressignificados "favorecendo modos colaborativos de aprendizagem" (BRAGA, 2007, p. 193). Esses modos colaborativos de aprendizagem são, conforme Heemann e Leffa (2013), uma das potencialidades da Educação a Distância (EaD), em que a interação, participação e colaboração, possibilitam a formação de uma comunidade, definida pelos autores como:

[...] uma associação de pessoas interagindo que possuem um relacionamento baseado na reciprocidade e compartilhamento de valores e práticas sociais. Ainda, a comunidade é formada por membros que almejam resultados "quase" semelhantes e para isso partilham objetivos/motivos comuns (HEEMANN; LEFFA, 2013, p. 71).

Para Heemann e Leffa (2013), na EaD, a formação de uma comunidade é essencial para que se construam conhecimentos de forma significativa; no entanto, a estruturação dessa comunidade deve ser fomentada de forma proposital, para que se alcancem os objetivos 
pedagógicos. Nesse sentido, a proximidade entre os participantes é elemento primordial e, para que ocorra, a interação é elemento propulsor.

Gonçalves (2011, p. 131) corrobora com o entendimento de que as interações entre os participantes do curso são motivadoras da construção de comunidades virtuais:

Para que o grupo se transforme em uma comunidade virtual, deve apresentar objetivos comuns, sentimento de comunidade entre seus participantes, sendo a interação o principal fator de união entre eles. Consequentemente, uma comunidade de aprendizagem em rede engloba os aspectos referentes à comunidade virtual, desde que, em cooperação, produza o conhecimento num aprendizado coletivo do grupo (GONÇALVES, 2011, p. 131).

Segundo a supracitada autora, as interações alcançam o patamar quando os alunos também produzem as mensagens. Para tanto, defendemos que haja um constante incentivo e convite à participação, a fim de que se oportunize espaços em que os estudantes possam se expressar e interagir, desenvolvendo seus pontos de vista, compartilhado seus anseios e encontrando parceiros para a resolução de problemas comuns, efetivando-se como protagonistas na construção do conhecimento. No AVA, essas mensagens podem ser produzidas pelos alunos de diversas formas: com textos escritos, áudios, vídeos, imagens, símbolos, de acordo com cada tarefa proposta.

Em nossas ações pedagógicas utilizamos o AVA Moodle, que é usado na Unipampa tanto para cursos de graduação da modalidade a distância - Moodle EAD - quanto como plataforma de apoio aos cursos presenciais. É um ambiente de fácil acesso, que reúne diversas ferramentas que permitem a disponibilização de conteúdo, realização de atividades e interação entre as pessoas em uma sala on-line.

AVAs como o Moodle permitem integrar diferentes mídias, linguagens e recursos. $O$ uso dessas ferramentas, porém, depende dos objetivos de aprendizagem e do público-alvo. O nosso olhar está para o AVA como espaço de interação, que não está limitado apenas ao gerenciamento de informações e realização de tarefas. Assim, utilizamos como principal ferramenta de interação os fóruns de discussão que, conforme Heemann e Leffa (2013, p. 103), "são espaços colaborativos virtuais nos quais os alunos se engajam na discussão sobre um tópico motivador".

Tais escolhas pedagógicas se dão por concordarmos que "aprendemos nas interações, na colaboração e na troca. Sendo assim, as interfaces devem favorecer a comunicação, de forma plural e objetivada pelo contexto e conteúdo a serem desenvolvidos" (MILL et al., 2012, p. 227). Corroborando com esse pensamento, Maturana (2002, p. 59) também nos traz uma perspectiva em que o fenômeno do aprender-conhecer se dá na convivência, nos encontros recorrentes, pois "toda interação implica num encontro estrutural entre os que interagem, e todo encontro estrutural resulta num desencadilhamento ou num desencadeamento de mudanças estruturais entre os participantes do encontro". Dessa forma, estando juntos, presencial ou digitalmente, mudamos nossa forma de ser e de agir.

Desde 2017, já foram ofertados pelo nosso núcleo 15 cursos on-line com diversas temáticas: Gestão e organização dos estudos; Gramática da língua portuguesa; Práticas de letramentos acadêmicos; e Rede de apoio ao estudante na Unipampa. Todos os cursos são planejados e 
elaborados numa perspectiva que tem como foco a interação, a colaboração e o aluno como protagonista do processo educativo.

Ao longo desses anos, foi possível observar um considerável aumento do interesse e da participação dos estudantes nessa modalidade de ensino, o que tem favorecido a ampliação das temáticas dos cursos, bem como a aproximação dos estudantes com o NuDE. Tal aproximação é fomentada pelas interações estabelecidas por meio da Educação a Distância e, por consequência, das comunidades que se formam a partir delas em cada contexto virtual específico. Além disso, por intermédio dos feedbacks recebidos dos alunos que concluem os cursos on-line, é possível planejar e implementar outras estratégias de acompanhamento pedagógico e apoio às atividades acadêmicas.

Diante disso, ao voltarmos o olhar para nosso compromisso social e profissional, consideramos que ao ingressarmos no corpo técnico de uma universidade recém-implantada, numa região de contextos históricos e geográficos desfavoráveis, cujos estudantes, em sua maioria, pertencem a uma camada da população que há anos esteve às margens do Ensino Superior e, assim sendo, muitas vezes não está familiarizada às práticas acadêmicas, assumimos vários desafios profissionais que refletem em nossas práticas cotidianas. Essas práticas têm sido voltadas a práticas de apoio por meio da Educação a Distância, como estratégia para estarmos presentes e próximas aos estudantes. A noção de presença e proximidade diz respeito ao encontro entre educadores e estudantes proporcionado pelos AVAs, visto que estes:

[...] criam condições adequadas para uma nova noção de presença, isto é, cria um ambiente para a convivência de educadores e estudantes que reconfigura a noção de presença e ausência (momento ou tempo de sincronia) ou distância e proximidade (lugar de encontro ou de presença), como tradicionalmente ocorre numa sala de aula presencial. (MILL et al., 2012, p. 22).

Desse modo, ressaltamos ainda que, tais experiências com a EaD, modalidade que, segundo Moreira e Schlemmer (2020), possibilita aprendizagens que ultrapassam paradigmas tradicionais de concepção empirista, contribuíram para que em um momento de crise sem precedentes, como a causada pela pandemia, estivéssemos preparadas para dar um passo além e transformar nosso ambiente de trabalho, nossa sala presencial, na Sala Virtual de Apoio Pedagógico ao estudante que apresentaremos a seguir.

\subsection{0 apoio pedagógico durante as Atividades de Ensino Remoto Emergenciais}

Com as restrições impostas pelo coronavírus e a suspensão das aulas presenciais no ano de 2020, a Unipampa estabeleceu a oferta de Atividades de Ensino Remoto Emergenciais, ou seja, "atividades pedagógicas não presenciais, síncronas e assíncronas, desenvolvidas para garantir o atendimento aos discentes com o uso de tecnologias de apoio à aprendizagem, durante o período de distanciamento social" (UNIPAMPA, 2020, p. 01).

O estabelecimento desse modelo de ensino impôs também a busca de novas alternativas para o acompanhamento pedagógico dos estudantes do Campus Dom Pedrito. A partir dessa demanda e dos desafios que já acompanhavam nossa realidade no contexto acadêmico, 
destacamos nossas vivências profissionais por meio de práticas pedagógicas implementadas durante a pandemia: criação da Sala Virtual de Apoio Pedagógico ao Estudante na plataforma Moodle, cujo objetivo é ter um espaço de interação durante as AEREs, com atividades síncronas e assíncronas.

Como já mencionamos, a experiência com os cursos on-line que vinham sendo desenvolvidos como ações de apoio aos estudantes foi fundamental para podermos preparar e oferecer um espaço virtual que pudesse auxiliar também nesse período em que o apoio pedagógico não teria nenhuma atividade presencial, mas que não poderia, em hipótese alguma, ser descontinuado, tendo quem vista que, mais do que nunca, os estudantes careciam de auxílio, pois enfrentam novos e diferentes desafios acadêmicos - que iam desde o manuseio e acesso às ferramentas e plataformas digitais, até a organização para o estudo em casa e conhecimento dos sistemas institucionais.

Importante ressaltar que em tal cenário concordamos com Moreira e Schlemmer (2020, p. 6) ao dizer que:

\begin{abstract}
A tecnologia sozinha não muda as práticas pedagógicas, sendo que para maximizar os benefícios da inovação tecnológica, principalmente os que se referem as TD, importa alterar a forma como se pensa a educação. Não é uma utopia considerar as tecnologias como uma oportunidade de inovação, de integração, inclusão, flexibilização, abertura, personalização de percursos de aprendizagem, mas esta realidade exige uma mudança de paradigma.
\end{abstract}

A partir dessas premissas, nossas práticas ganham sentido e qualidade. Sendo assim, norteadas por referenciais que defendem o uso de recursos tecnológicos como potenciais para inovação na educação, desde que utilizados com objetivos claros e metodologias adequadas ao Ensino Remoto, planejamos e implementamos um projeto pioneiro em nosso contexto universitário: a Sala Virtual de Apoio Pedagógico.

\title{
2.3 Sala Virtual de Apoio Pedagógico: apresentação e configuração
}

A Sala Virtual de Apoio Pedagógico foi criada e configurada na plataforma Moodle durante os meses de abril a julho de 2020, período em que a equipe idealizou e planejou, com base nos referenciais já apresentados, as metodologias de interação que seriam mais adequadas ao objetivo de manter a nossa presença e fomentar a criação e manutenção das redes de apoio entre e para os estudantes, tendo em vista as especificidades e os novos desafios que a pandemia nos impunha naquele momento.

As atividades dos estudantes na sala tiveram início no mês de agosto de 2020, mesmo período em que se iniciavam as AEREs na instituição. A divulgação da Sala Virtual e o convite para acessá-la foram feitos através de e-mail institucional, de redes sociais e da página do Campus. 0 acesso é liberado para qualquer pessoa da comunidade acadêmica, sem necessidade de préinscrição ou outra forma de restrição. A abertura oficial da Sala Virtual de Apoio Pedagógico foi realizada em um encontro on-line, por meio da ferramenta do Moodle, o BigBlueButton, no dia 23 de setembro. Nessa oportunidade, apresentamos à equipe - profissionais do NuDE e 
monitores - uma demonstração da sala virtual e roda de conversa com a participação da psicóloga da PRAEC.

A Sala Virtual foi organizada por meio da estrutura de tópicos do Moodle, sendo que cada tópico foi destinado a uma ação pedagógica específica. No primeiro tópico, desejando as boasvindas, inserimos uma imagem, criada a partir da ferramenta Canva, que faz lembrar o aconchego de uma sala física, com o intuito de materializar nosso local de acolhida. Logo após, utilizamos outro tópico para inserir o logotipo oficial do NuDE e inserimos vídeos, por meio do recurso rótulo, com a apresentação pessoal dos membros e dos objetivos da Sala. A Figura 1 ilustra os primeiros recursos inseridos no AVA da Sala Virtual.

\section{Figura 1: Sala Virtual de Apoio Pedagógico}

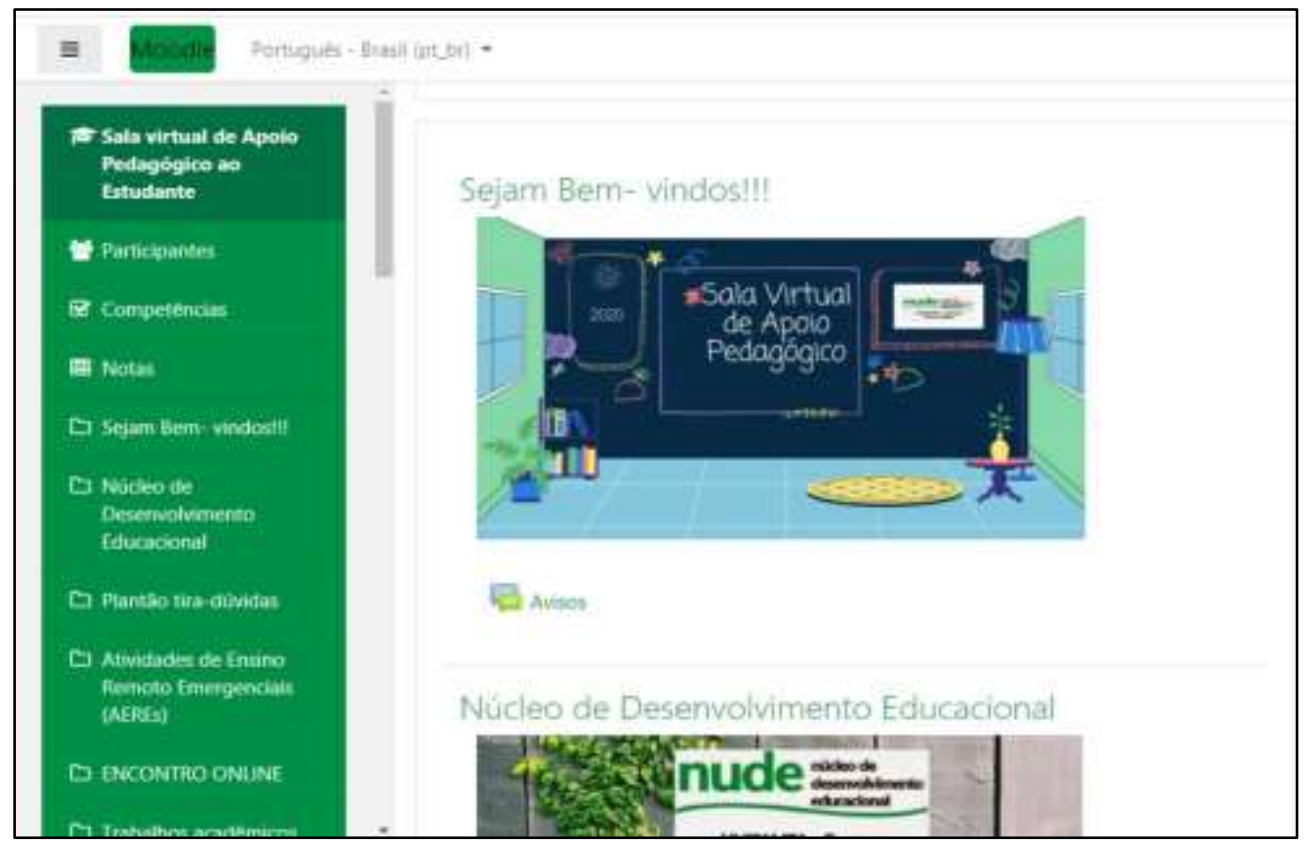

Fonte: adaptado de Moodle cursos presenciais/Unipampa, 2020.

A Sala Virtual conta também com o Plantão tira-dúvidas, utilizado por meio do recurso chat, conforme ilustra a Figura 2. Nesse ambiente, os estudantes podem participar em dias e horários previamente estabelecidos; o objetivo é que os estudantes possam entrar em contato de maneira síncrona com nossa equipe, sempre quando tiverem dúvidas ou necessitarem de algum auxílio. A administração dos chats é feita por estudantes monitoras, que ficam on-line para atender aos estudantes participantes, responder seus questionamentos, auxiliar no acesso às ferramentas da própria plataforma ou outras ferramentas usadas pelos docentes nas disciplinas cursadas de forma remota, bem como dar sugestões ou encaminhar documentos e materiais de leitura. 


\section{Figura 2: Plantão tira-dúvidas}

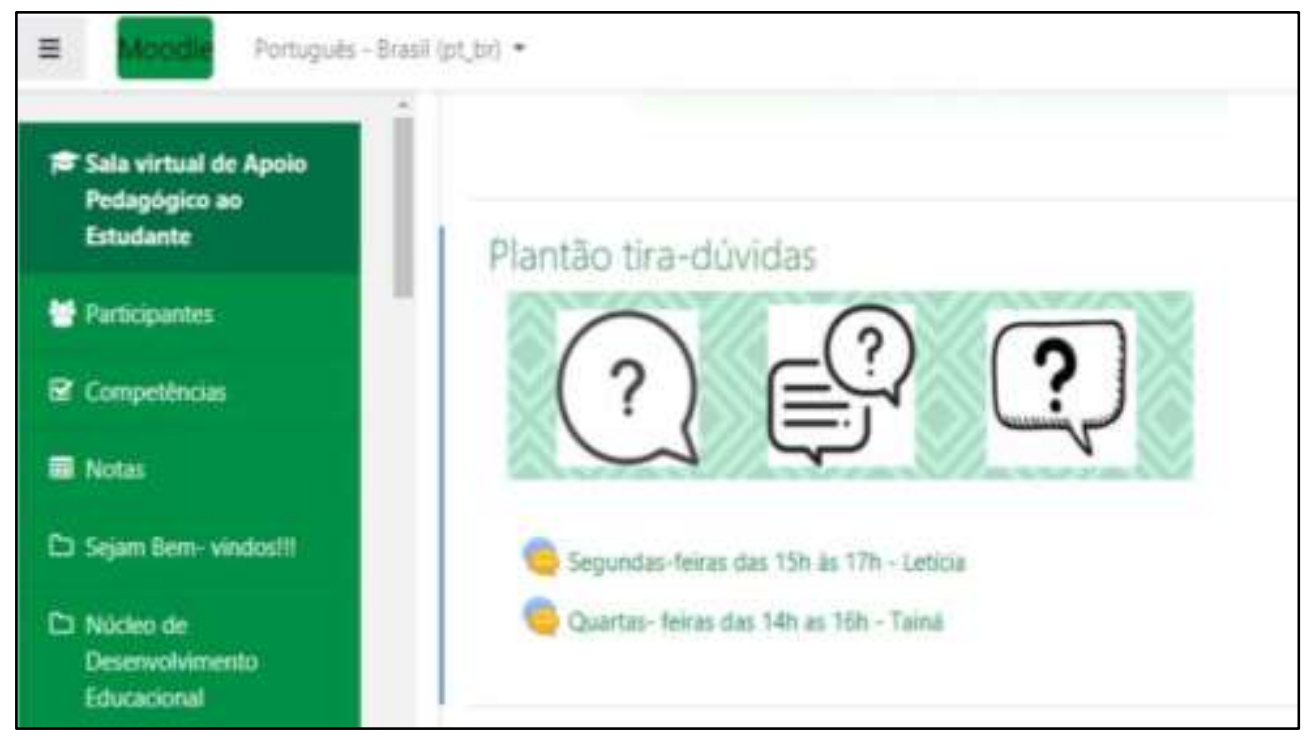

\section{Fonte: adaptado de Moodle cursos presenciais/Unipampa, 2020.}

Além dos recursos apresentados, os quais estão fixados de maneira permanente nos primeiros tópicos de nossa Sala, as informações sobre o dia a dia na universidade, os tutoriais simples e acessíveis - e as orientações sobre os documentos institucionais são disponibilizados principalmente no formato de minicursos, sendo que todos os materiais são elaborados pela equipe do núcleo, especificamente para esse fim.

Cada minicurso é elaborado em um tópico específico do AVA e fica disponibilizado somente em um determinado período. Os estudantes que estão inscritos na Sala Virtual podem escolher os minicursos que desejam acessar; essa participação não é obrigatória, mas incentivada, tendo em vista o alcance dos objetivos pedagógicos. Cabe ressaltar que o principal intuito da Sala Virtual é manter a presença da equipe pedagógica, ou seja, a proximidade com os estudantes por meio de um ambiente virtual interativo e da formação de redes de apoio a partir da comunidade colaborativa on-line.

Sendo assim, o fato de os estudantes participarem pontualmente de uma ou de várias atividades da sala; de compartilharem suas dúvidas, anseios e opiniões com os demais colegas por meio das escritas nos fóruns - ou dos seus feedbacks, comentários e avaliações realizados por meio de questionários ao final de cada minicurso -, já nos permitem afirmar que a comunidade está se formando e se consolidando, além de oferecer subsídios para que nossa equipe possa ampliar e intensificar outras ações, demandadas a partir das necessidades apontadas pelos próprios estudantes.

Por outro lado, como forma de incentivar participações mais consolidadas, ao finalizar cada minicurso, o aluno pode solicitar a comprovação de sua participação. Esta poderá ser validada como Atividade Complementar de Graduação (ACG) na modalidade ensino. Por meio do acompanhamento permanente das ações dos participantes em cada atividade proposta, podemos verificar aqueles que tiveram interesse em finalizar cada minicurso, ou seja, os que acessaram os materiais de apoio, interagiram nos fóruns e realizaram a respectiva atividade final 
- em que verificamos os conhecimentos adquiridos e solicitamos avaliação das metodologias de ensino utilizadas.

Assim, temos duas principais formas de participação estudantil na Sala Virtual: a primeira é a participação pontual, acessando um ou mais materiais de apoio ou recursos de interação com os participantes, de acordo com o interesse individual específico de cada indivíduo; a segunda é por meio da presença integral nos minicursos e solicitação de comprovante de participação.

Nesse contexto, de agosto de 2020 - início das atividades virtuais na sala - até dezembro de 2020 - encerramento do primeiro semestre acadêmico de 2020 - foram disponibilizados três minicursos. $O$ primeiro, entre os meses de agosto e setembro de 2020, tinha como tema Atividades de Ensino Remoto Emergenciais (AEREs), conforme ilustra a Figura 3. O objetivo desse minicurso foi auxiliar o estudante na adaptação às AEREs, informando sobre essa modalidade de ensino, normas institucionais para o período, bem como trazendo tutoriais sobre sistemas e plataformas digitais usados na Unipampa - portal Unipampa, e-mail institucional, GURI, Moodle e Classroom. A carga horária total foi de cinco horas.

Figura 3: Minicurso Atividades de Ensino Remoto Emergenciais (AEREs)

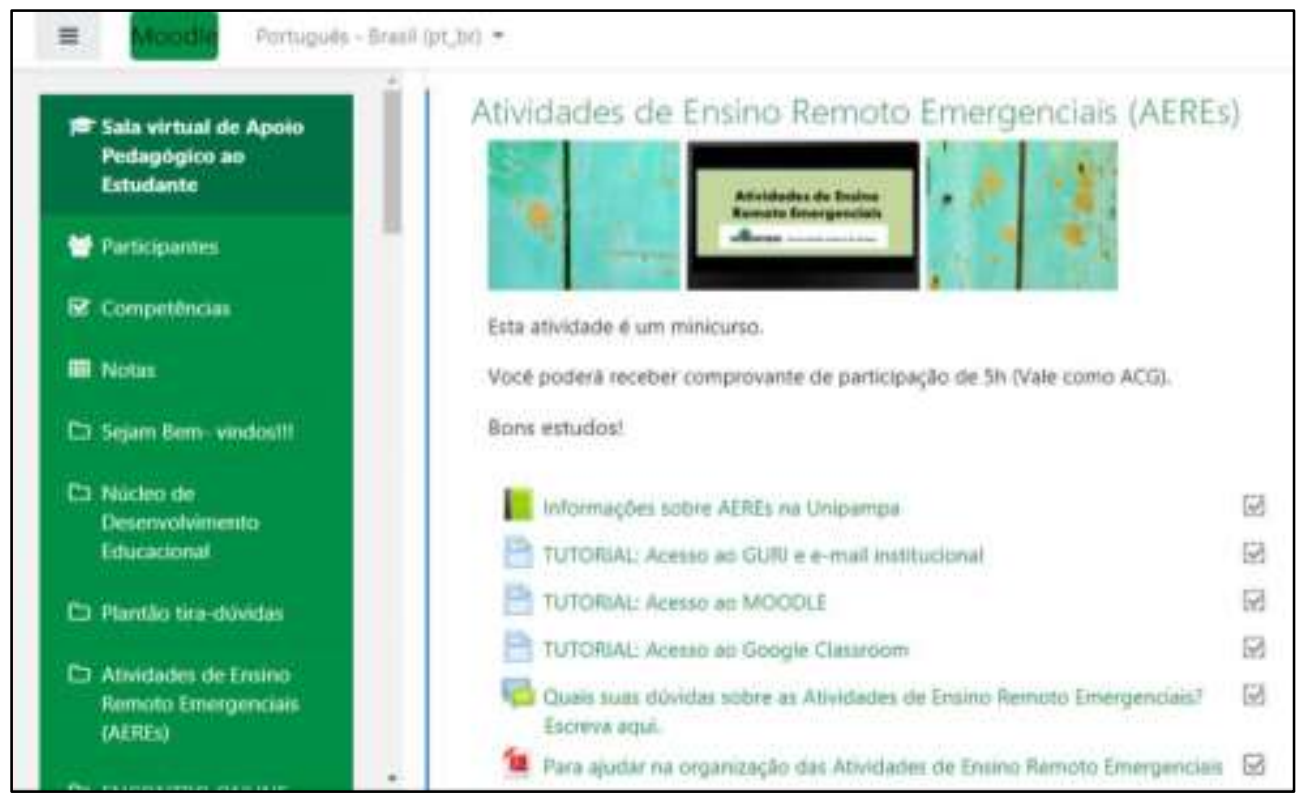

Fonte: adaptado de Moodle cursos presenciais/ Unipampa, 2020.

Metodologicamente, nesse primeiro minicurso, utilizamos no início o recurso livro para exposição das principais informações referentes às Atividades de Ensino Remoto Emergenciais, que passaram a ser a única opção de oferta de ensino do primeiro semestre acadêmico de 2020 em meio à pandemia. Logo após, inserimos como recursos alguns vídeos com tutorial para acesso e utilização das principais ferramentas institucionais que seriam utilizadas para o Ensino Remoto. Depois do acesso a esses materiais, os estudantes deveriam participar do fórum de discussões e interações e, por fim, participar da atividade final do curso.

O segundo minicurso, disponibilizado em outubro de 2020, teve como temática Elaboração e apresentação de trabalhos acadêmicos, conforme ilustra a Figura 4; o objetivo foi oferecer ao estudante orientações sobre ferramentas do Google - Google documentos, Google 
apresentações, Google Meet - que pudessem ser usadas para a produção de textos, trabalhos em grupo e apresentação de trabalhos. A carga horária total foi de 10 horas.

Figura 4: Minicurso Elaboração e apresentação de trabalhos acadêmicos

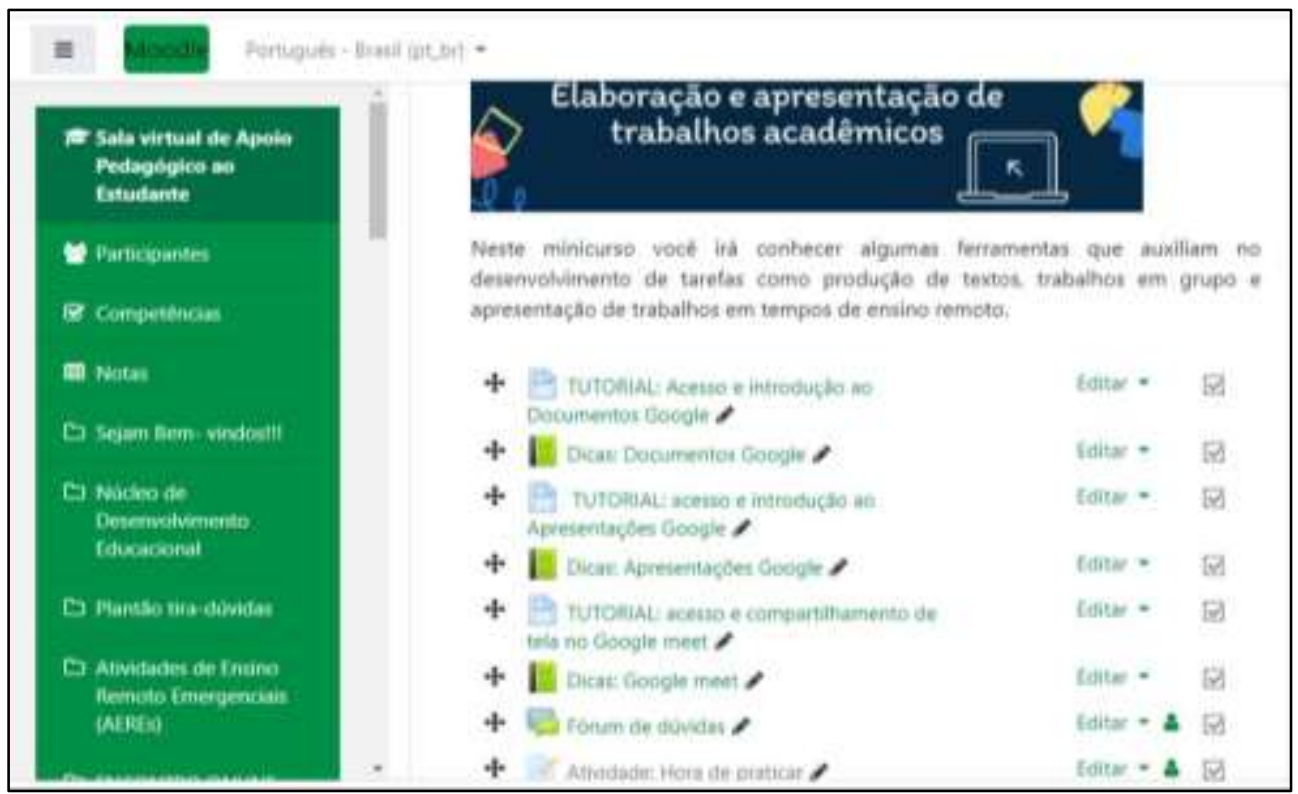

Fonte: adaptado de Moodle cursos presenciais/ Unipampa, 2020.

Com metodologia similar ao primeiro minicurso, utilizamos o recurso livro para expor as principais características e usos de cada ferramenta digital e do recurso vídeo para os tutoriais. Para além, com o recurso diário, propusemos uma atividade prática em que, após assistirem aos tutoriais, deveriam criar um texto ou uma apresentação contando a experiência individual com o Ensino Remoto e compartilhar o link do arquivo com a turma. Finalmente, para receber o comprovante de participação, deveriam também realizar a atividade final do curso.

Por fim, o terceiro e último minicurso, disponibilizado entre os meses de novembro e dezembro de 2020, teve como tema Encerrando o semestre na Unipampa, conforme mostra a Figura 5. O objetivo desse minicurso foi investigar como os estudantes se sentiam emocionalmente com as AEREs e orientar o encerramento do semestre com dicas para deixar tudo organizado antes das férias. A carga horária total foi de 5 horas. 
Figura 5: Minicurso Encerrando o semestre na Unipampa

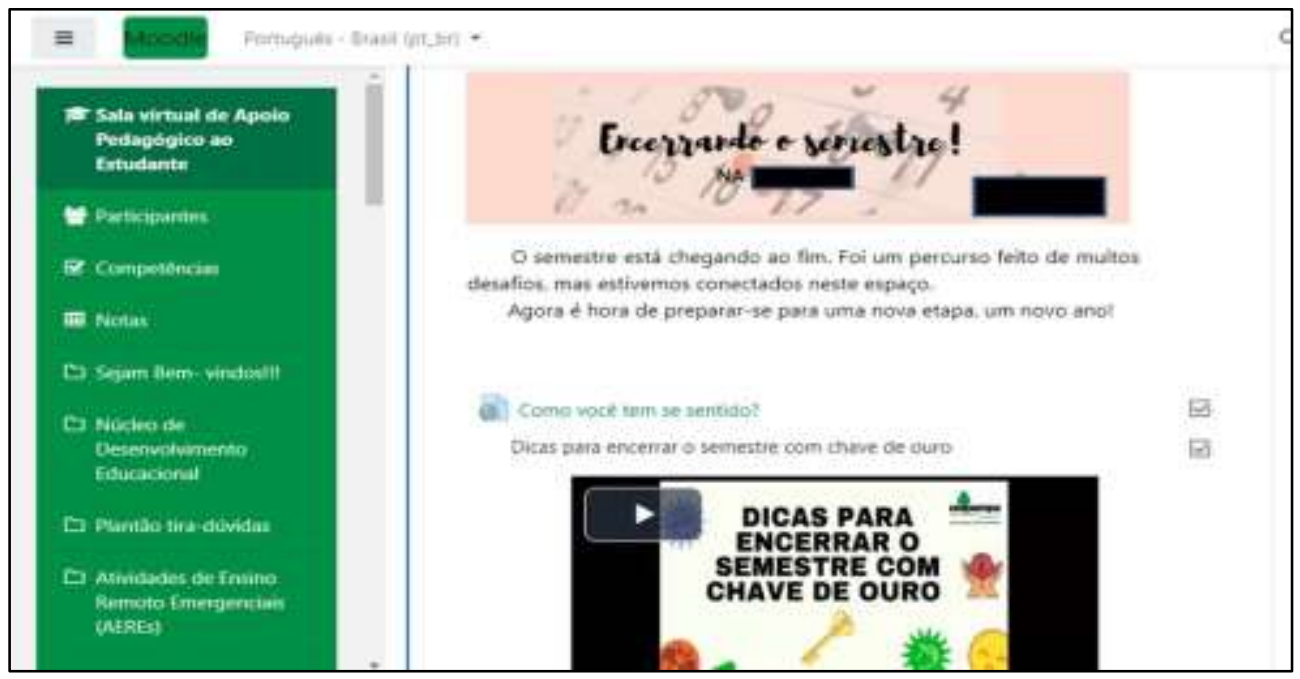

Fonte: adaptado de Moodle cursos presenciais/ Unipampa, 2020.

Seguimos uma metodologia um pouco diferente no último minicurso em que, além de disponibilizarmos o material de apoio pelo recurso rótulo, utilizamos um questionário para que os participantes expressassem sentimentos e emoções que afloravam ao final de um ano tão desafiador, em que todos tivemos muito a aprender, principalmente no que se refere aos processos de ensino e de aprendizagem mediados pelas tecnologias. Tal atividade, além de fomentar reflexões pessoais dos estudantes, nos ajudou a conhecer melhor a comunidade acadêmica e a qualificar nossos serviços.

De maneira geral, os minicursos estão configurados com recursos como questionários e vídeos, mas principalmente por fóruns, diários e tarefas que oferecem aos estudantes a oportunidade de interagir, tirar dúvidas e avaliar seus conhecimentos e suas experiências. Como já mencionamos, aqueles estudantes que concluem os minicursos recebem atestado de participação. No período de análise do presente artigo, de agosto até dezembro de 2020, ao todo 24 estudantes concluíram os minicursos, recebendo certificação.

A presença e participação dos estudantes na Sala Virtual tem apontado perspectivas positivas em relação ao papel do apoio pedagógico, como podemos observar em alguns comentários sobre os minicursos, registrados pelos estudantes no AVA Moodle após a conclusão das atividades:

\footnotetext{
"Parabéns, bem didático! Continuem assim!"; "O minicurso é essencial e didático, com informações de fácil compreensão para com os alunos."; "Ótimas informações e aprendizagem."; "Sempre superando as expectativas."; "O minicurso é didático de fácil compreensão para com os alunos."; "Quero agradecer pelo curso, pude sanar algumas dúvidas e com apoio de vocês me sinto no caminho certo". (DADOS DA PESQUISA, 2020).
}

O retorno que recebemos por meio de comentários como os apresentados acima, bem como as sugestões de temas e atividades para a Sala virtual manifestados pelos estudantes, permitem que possamos planejar e elaborar novas ações que atendam suas necessidades e sejam coerentes com a nova realidade. Dentre os temas e atividades sugeridas pelos estudantes estão: 
cursos e tutoriais de outras ferramentas e plataformas digitais, além das apresentadas na Sala; palestras motivacionais; organização para as aulas remotas; abordagem dos temas confiança, ansiedade, depressão e saúde emocional; atividades de interação entre alunos, professores e funcionários; criação de um grupo de debate.

No primeiro mês de funcionamento, 51 estudantes fizeram o acesso à plataforma; e até o mês de dezembro de 2020 mais 28 alunos visitaram e participaram da sala, totalizando 79 discentes que, de alguma maneira, estiveram próximos ao nosso Núcleo, por meio da Sala Virtual. Nossa experiência com a implementação e efetivação da Sala Virtual de Apoio Pedagógico ao estudante é pioneira na instituição, mas nos leva a pensar, por um lado, na manutenção e ampliação das nossas atividades utilizando esse recurso e, por outro, na possibilidade de materialização de um ambiente profissional colaborativo, em rede.

\section{PARA FINALIZAR: PRÁTICAS VIRTUAIS DE APOIO AO ESTUDANTE PARA ALÉM DO CENÁRIO PANDÊMICO}

Pensar o apoio pedagógico no Ensino Superior em meio a um período de educação emergencial, em que aulas presenciais foram suspensas como medida de enfrentamento à pandemia do novo coronavírus, leva-nos a refletir sobre paradigmas e referenciais que fundamentam nossas práticas cotidianas, especialmente sobre o uso de tecnologias educacionais, tendo em vista a necessidade de continuidade das atividades e serviços oferecidos por instituições de ensino. Partimos, então, do entendimento que aprender envolve interação entre aqueles que participam do processo e do desafio de manter a proximidade em tempos de distanciamento social.

A oferta de cursos on-line aos estudantes da Unipampa que vinha sendo realizada pelo NuDE - Campus Dom Pedrito nos últimos anos colaborou para a implementação de novas práticas de apoio pedagógico durante as Atividades de Ensino Remoto Emergenciais, a partir da oferta de um espaço virtual acolhedor e dinâmico. A sala física de apoio pedagógico foi substituída por uma sala virtual, que permitiu e favoreceu o acompanhamento pedagógico dos estudantes, minimizando os impactos da distância física no ano de 2020.

A Sala Virtual de Apoio Pedagógico é um espaço de interação que buscou acolher e auxiliar os estudantes de cursos presenciais do Campus Dom Pedrito frente a uma nova realidade, por meio de práticas pedagógicas virtuais que buscaram orientar quanto ao uso e acesso às ferramentas e plataformas digitais; à organização para o estudo em casa; ao conhecimento dos sistemas institucionais, além de motivar a presença e o engajamento dos discentes no seu próprio processo educativo.

Nossa experiência demonstra que as práticas virtuais de apoio ao estudante, desenvolvidas em um momento desafiador, tiveram impactos positivos, pois garantiram a proximidade e 0 fortalecimento de vínculos com a comunidade acadêmica. Desse modo, compreendemos que nossas práticas vão além da adaptação a um período excepcional, ou seja, são práticas dotadas de sentido, permeadas por uma concepção epistemológica que valoriza a interação e a colaboração. Destacamos, ainda, a possibilidade de migrar nossas ações profissionais para o âmbito coletivo, incentivando uma cultura profissional colaborativa. 
Por fim, visamos à continuidade e ampliação das estratégias adotadas durante a pandemia, bem como o estudo sistemático das interações sociais efetivadas por meio das escritas dos estudantes na Sala Virtual de Apoio Pedagógico, a fim de nortear nossas ações com vistas à consolidação do apoio pedagógico no Ensino Superior. Sendo assim, esperamos com este relato de experiência fomentar novas discussões sobre o uso das tecnologias digitais e espaços virtuais de interação.

\section{REFERÊNCIAS}

BRAGA, D. B. Letramento na internet: o que mudou e como tais mudanças podem afetar a linguagem, o ensino e o acesso social. In: KLEIMAN, A. B.; CAVALCANTI, M. C. (Org.). Linguística aplicada: suas faces e interfaces. Campinas: Mercado de Letras, 2007.

BRASIL. Lei ${ }^{\circ} 13.979$, de 6 de fevereiro de 2020. Dispõe sobre as medidas para enfrentamento da emergência de saúde pública de importância internacional decorrente do coronavírus responsável pelo surto de 2019. Diário Oficial União: seção 1, Brasília, DF, n. 27, p. 1, 7 fev. 2020. Disponível em: https://www.in.gov.br/en/web/dou/-/lei-n-13.979-de-6-de-fevereiro-de-2020-242078735. Acesso em: 15 nov. 2020.

DIAS, C. E. S. B.; SAMPAIO, H. Serviços de apoio a estudantes em universidades federais no contexto da expansão do ensino superior no Brasil. In: DIAS, C. E. S. B. et al. (Orgs.). Os serviços de apoio pedagógico aos discentes no ensino superior brasileiro. São Carlos: Pedro \& João Editores, 2020.

GONÇALVES, M. I. R. Educação na cibercultura. Curitiba: CRV, 2011.

HEEMANN, C.; LEFFA, V. J. Educação a distância: a formação de comunidades virtuais de aprendizagem. Pelotas: EDUCAT, 2013.

MATURANA, H. R. Emoções e linguagem na educação e na política. Belo Horizonte: UFMG, 2002.

MILL, D. et al. Prática Polidocente em ambientes virtuais de aprendizagem: reflexões sobre questões pedagógicas , didáticas e da organização sociotécnica. In: MACIEL, C. (Org.). Educação a distância: Ambientes virtuais de aprendizagem. Cuiabá: EduFMT, 2012.

MOREIRA, A.; SCHLEMMER, E. Por um novo conceito e paradigma de educação digital onlife. Revista UFG, Goiânia, v. 20, n. 26, 2020. Disponível em: https://www.revistas.ufg.br/revistaufg/article/view/63438. Acesso em: 01 dez. 2020.

PINHEIRO, P. A. Gêneros no mundo digital: Um meio de "transdisciplinarizar" a escola. In: GONÇALVES, A. V.; BAZARIM, M. (Org.). Interação, Gêneros e Letramento: A (re)escrita em foco. São Carlos: Claraluz. 2009.

SOARES, M. Novas Práticas de Leitura e escrita: letramento na cibercultura. Educação \& Sociedade, Campinas, v. 23, n. 81, p. 143-160, dez. 2002. Disponível em: http://www.scielo.br/scielo.php?pid=S010173302002008100008\&script=sci_arttext\&tlng=es. Acesso em: $01 \mathrm{dez} .2020$.

UNIVERSIDADE FEDERAL DO PAMPA (UNIPAMPA). Norma operacional $\mathbf{n} \mathbf{0} \mathbf{4} \mathbf{2 0 2 0}$. Diretrizes operacionais para oferta das Atividades de Ensino Remoto Emergenciais: AEREs. Bagé: UNIPAMPA, 2020. Disponível em: 
https://sites.unipampa.edu.br/prograd/files/2020/08/norma-operacinal-n-o-4-2020_diretrizes-

operacionais-para-oferta-das-atividades-de-ensino-remoto-emergenciais.pdf. Acesso em: 01 dez. 2020.

UNIVERSIDADE FEDERAL DO PAMPA (UNIPAMPA). Plano de Desenvolvimento Institucional 2014-2018. Bagé: UNIPAMPA, 2013. Disponível em: https://sites.unipampa.edu.br/pdi/files/2014/01/PDI-UNIPAMPA2014-2018.pdf. Acesso em: 01 dez. 2020. 